International Journal of Social Research
(ISSN:2576-5531)

\title{
Study on Analysis of the Theoretical Abstraction of Economic Sociology and Embeddedness on Economic Action
}

\section{Tiantian Tang}

Dongbei University of Finance and Economics, No. 217 jianshan street, dalian, liaoning, China.

\begin{abstract}
Economics believes that economic behavior in the pursuit of

interests will not involve any social behavior or relationship. Tiantian Tang perspective of economic sociology, starting from the perspective of embeddedness, expounding and explaining economic behavior, and proposing several theoretical abstract researches on "economic behavior", in order to provide some guidance and help for relevant researcher.
\end{abstract} However, with the continuous development of society, personal Dongbei University of Finace and economic behavior does not fully encourage and atomize, but Economics, No.217 jiangshan a clock is in the process of changing social relations. From the street, dalian, liaoning, China.

Keywords: Economic sociology; Embeddedness; Economic behavior; Theoretical abstraction
*Correspondence to Author:$$
\text { street, dalian, liaoning, China. }
$$

How to cite this article:

Tiantian Tang. Study on Analysis of the Theoretical Abstraction of Economic Sociology and Embeddedness on Economic Action. International Journal of Social Research, 2019; 3:34

\section{eScî̀Pub}

eSciPub LLC, Houston, TX USA.

Website: http://escipub.com/ 


\section{Introduction}

One of the most enduring topics in social economics is the critical evaluation of economics. To be more precise, economic sociology is a unified definition of the critical process of economic modelling strategies. The modelling strategy of economics is based on the economics of Jiading. But with the constant development of the times, An important pertinent concept of the concept of embeddedness in economic sociology, Economic sociologists use it as a unique way of understanding economic processes. Embeddedness is a structure of decision-making culture, society, politics, and cognition in an economic situation. It is closely related to the actors and the social environment. In this regard, from the perspective of economic sociology and embeddedness, the theoretical abstraction of economic action has significant practical value.

\section{The limitations of economics on economi- c behavior}

Economics has always been carried out in a rational way of economic behavior. This modeled strategy basically clarifies that people's economic behavior takes place independently of decision-making. The improvement of inform ation and the performance of free exchanges, and the behavioral process is always aimed at maximizing the benefits. And the process of production, exchange and distribution is determined by the target. [1] In a competitive market, Both parties to the transaction need to obtain the maximum benefit with the least cost, and there is no social relationship. At this time, the influence of factors such as social structure on the subject will be more prominent. At the same time, it also negates the influence and role of the behavior itself on the surrounding people and the environment. In the course of specific activities, There are many economic problems in economic behavior. For example, in the last century, for the issue of trust, although economic actors are keen to pursue personal interests, But opportunistic behavior is difficult to avoid, and it is necessary to guarantee the stability of order. In the new institutional economics, institutional arrangements can guarantee economic order and promote overall efficiency, Or it is to prevent the morality of opportunism in terms of universality. However, because of the diversity and complexity in the real world, Can lead to people's behavior can not be separated from society and independent existence, At this time, the social structure will greatly affect the normal operation of the entire economic system. Economics seems to lack serious explanatory power ${ }^{[2]}$, In this regard, during the interpretation of human economic behavior, There are many insurmountable problems in the absence of economics, which is also the key to sociologists integrating economics and sociology. Further discussion of economic behavior can better grasp more opportunities for economic development. At this point, it can be criticized by insufficient socialization of economic behavior or excessive socialization. And further highlight the embedded relationship of economic behavior in the social relationship network, I believe that social relations have also played a significant role in building economic behavior. This result also directly stimulated the process of economic activity. And it will be clearly defined as a social person first, and then the subsequent social behavior will be decided. No link or process can be absolutely separated from society in a rational way. Social factors will largely determine how people maximize their behavior.

\section{Economic behavior is embedded in social}




\section{structure}

In the process of long-term economic research, the ongoing economic sociologists are put forward about economic behavior embedded in social relations theory, economic behavior belongs to a kind of special forms of social behavior, researchers in the 17th century when it is put forward about the relative system can better promote the development of overseas trade, subsequent catches the relationship between different generations some businessmen found that between merchant families intermarry rate is relatively high, high mixing rate also prompts the integration of the whole group, and after the restoration of the monarchy and speculators to build the relationship, lead to the formation of the merchant community. [3] In the 20th century, people conducted targeted studies on the factors and commodity markets in the Yangtze river delta, and found that the credit market in the Yangtze river delta was affected by the principle of reciprocity and the principle of maintaining vitality, and the labor market was also dominated by social relations. According to the interpretation of these phenomena, it is believed that there must be noneconomic rational behavioral motivation, that the realization of human rights, status and sociality is directly related to social network, and that all behaviors can be realized only after being amplified and reflected in the social background. According to this phenomenon, bank loans, Banks as loans for borrowers who do not reason to accept higher unfamiliar customers, but will choose some familiar and lending rates are relatively low long-term customers, also this way an act against the interests of the apparent violation of the principle of economic benefit maximization, the reason lies in the mutual trust between Banks and long-term customers with human relations, embedding performance lies in social relations and be a restraint on economic behavior, illegal or unethical behavior between each other will be brought to the attention of the higher. In contemporary society, although the economic behavior is more market structure, but the market itself has certain specific social structure, this structure is essentially a specific type of interaction, when people engage in economic activities of tangible or intangible market at the same time, the role of rules and factors such as social relations will be more obvious. As the main carrier of economic activities, the market itself has the more prominent social relationships, people engage in economic activities in the middle of the market will also involve more social norms, legal principle and relationship factors such as social value, cultural environment, so we can clear the moral order and standardization of market economic activity is a kind of representation of the behavior. [4] In addition, some studies believe that economic behavior will be constrained due to social relations. In the process of market education, if there are two merchants selling the same goods, both of them need to guarantee the delivery within the same period, there is no doubt that rational agents will choose the one with higher credibility to trade.

\section{Uncertainty and social theory}

An analysis of economic sociology can be achieved from the perspective of uncertainty, In the last century, there was research on the model of saving rational actors. It believes that without abandoning behavior theory as an understanding of economic processes, uncertainty can be reinterpreted and evaluated as risk from conventional equilibrium theory. At this time, the attention of the new system to economics argues for the concept of efficient in- 
stitutions. ${ }^{[5]}$ Not the same as the response to an uncertain question, Others believe that the model of rational actors needs to be abandoned more thoroughly. At this point, there needs to be a certain difference from the second response, and there is also a perception that the economic process should be understood. Can build a theory based on behavior, And a more refined standardized model that clarifies the rational calculation of relational rationality, Apply an alternative theory that meets the needs of decision making in complex economic situations and understand the experience of economic behavior. In this theory, economic behavior is clearly defined as the purpose of rationality, Representing the actor clearly wishing to enhance his own interests, This classification of economic behavior continues the distinction between social behavior and economic behavior. The focus of the division is that the characteristics of the latter are more in terms of utility. The orientation of utility involves not only satisfaction, but also the profit-making purpose of the modern capitalist economy. It is not only an opportunity, Because uncertainty can cause the structure to fail to meet expectations, The application of the optimization concept embodied at this time is an important flaw in economic theory. Mainly because it is impossible to bring the results of uncertainty into it. At this time, although the actor is still a reasonable behavior according to the purpose, But it may not be clear whether the best strategy can maximize benefits.

\section{Summary}

To sum up, Concerns about the concept of embeddedness have led economic sociology to ignore the question of the theoretical basis for behavioral and behavioral use in understanding economic situations, The theoretical abstrac- tion of sociology cannot simply apply the rational behavior model. The reason is that the uncertainty and complexity of the actors' experiences will show direct changes. Rational behavior is calculated and selected as a means of pre-targeting in the economic situation. The model theory of behavioral teleology has been basically presented on the basis of a concept of pragmatism. At this point, it can be used in the understanding of collaboration and innovation. From this perspective, how does the strategy need to start from the perspective of the actors' understanding of the social situation, And from a rational perspective, understand how to construct a social group's interpretation of expectations. The systematic relevance between micro and macro levels should be applied to the sociological understanding of strengthening economic processes. And adopt an alternative approach from the perspective of a rational actor's model. Rather than pure criticism.

\section{References}

1. Zhai Jiabin. The theoretical framework from system to action in economic sociology [J]. Theory of Learning, 2019, 31 (2): 44-45.

2. Lin Nan, Sun Zhunmo, Gao Bai, etal. The Economy Embedded in Social Network - Taking Network Social Network and Economy as an Example [J]. Sociological Review, 2018, 14(23): 244-245 .

3. Zheng Yang, Hu Jieren. Two-way embedding: Rural Economic Energy and Grassroots Government Behavior - Study on Urbanization from the Perspective of Political Sociology[J].Journal of Shanghai Administration College,2018,19(06 ):90-101.

4. Lai Wei. Granovetter's "embeddedness" theory and its application in social media research [J]. New Media Research, 2018, v.4; No. 82 (14): 15-17. 
Tiantian Tang. et al., IJSR, 2019; 3:34

5. Yan Jun, Li Tingting. Preference Change and Behavior Strategy of Bounded Rational Actors:

A Preliminary Theoretical Model [J]. Sociological Review, 2018, 6 (06): 18-30.

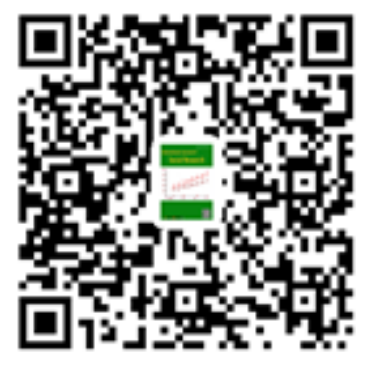

